\title{
Mudanças na Percepção Sobre o Processo de Envelhecimento: Reflexões Preliminares
}

\author{
Jacqueline de Oliveira Moreira ${ }^{1}$ \\ Pontificia Universidade Católica de São Paulo
}

\begin{abstract}
RESUMO - No presente artigo pretendemos realizar uma reflexão teórica sobre a mudança na percepção do processo de envelhecimento. Ela parte de uma concepção que vincula velhice a declínio, e a contrapõe a desenvolvimento, prosseguindo para uma posição que trabalha a perspectiva do desenvolvimento possível no envelhecimento. Pretendemos também, assim, localizar o ponto de partida do crescimento das pesquisas sobre o envelhecimento humano. A cultura contemporânea expressa um horror à velhice, na medida em que celebra o corpo jovem. Por outro lado, os preconceitos científicos em relação ao envelhecimento começam a ceder e abrir espaços para o avanço das pesquisas.
\end{abstract}

Palavras-chave: envelhecimento; desenvolvimento; life-span.

\section{Changes in Perception of the Aging Process: Preliminary Thoughts}

\begin{abstract}
In this article a theoretical reflection is carried out on changes in perception of the process of human aging. The starting point is a concept which links old age to decline, and opposes it to development. It then proceeds into a position which considers development to be possible in old age. Thus, we also intend to locate the point when such research began to grow. The contemporaneous culture abominates old age, as it celebrates the young body. On the other hand, scientific preconceptions regarding the aging process begin to fade and give way to advances in research.
\end{abstract}

Keywords: aging; development; lifespan.

Podemos definir a gerontologia como o estudo do processo de envelhecimento, com base nos conhecimentos oriundos das ciências biológicas, psicológicas e sociais (Neri, 1995; Mascaro, 2004). A primeira menção à necessidade da criação de um campo de estudo para o envelhecimento aparece em 1903, com Metchnikoff (1903, citado por Neri, 1995), mas somente depois de quase 50 anos teremos uma produção mais sistemática sobre o tema do envelhecimento. Podemos pensar que a proposta do Ciclo de Vida, de Erikson (1950/1998), é a primeira grande contribuição do campo da psicologia para a compreensão do envelhecimento. Por que este intervalo de quase cinquenta anos?

\section{O lugar do idoso nas sociedades tradicional e pós-tradicional}

A concepção que associa envelhecimento à ideia de declínio contribuiu, segundo acreditamos, para o intervalo de quase cinquenta anos entre os estudos sobre a gerontologia. Sabemos que os preconceitos em relação à velhice podem ser culturais, econômicos e até científicos, e que as sociedades pré-modernas, ou tradicionais (Dumont, 1985; Giddens, 1997), não apresentavam um preconceito cultural em relação ao idoso. Nessas sociedades, o ancião ocupava um lugar de destaque e respeito social, já que era o guardião da sabedoria e o responsável por transmiti-la aos mais jovens (Mascaro,

1 Endereço para correspondência: Av. Itaú, $\mathrm{n}^{\circ} 525-1^{\circ}$ subsolo Bairro Dom Cabral - Belo Horizonte, MG. CEP 30535-012. E-mail: jackdrawin@yahoo.com.br.
2004). Podemos pensar em tradição, que é a "cola" que une as ordens sociais pré-modernas, que mantém a ordem social. Uma conexão necessária, que garante a coesão social. A tradição é um meio organizador da memória coletiva, e revela a verdade histórica de um povo. Os guardiões dessa memória, dessa tradição têm muita importância para a sociedade, porque se acredita que eles são os agentes ou mediadores das pessoas (Giddens, 1997).

No entanto, não podemos deixar de mencionar que as sociedades clássicas apresentam várias construções míticas sobre a juventude eterna e a imortalidade, o que revela uma dificuldade em relação ao envelhecimento, mas, sobretudo, em relação à morte. Ademais, mesmo considerando o lugar de destaque do ancião nas sociedades tradicionais, isso não garante um espaço privilegiado de estudos sobre o envelhecimento, uma vez que será na sociedade moderna que teremos o crescimento da pesquisa cientifica. Assim, é preciso entender a passagem da era clássica para a moderna, e por que a ciência moderna não se interessa pelo estudo do envelhecimento.

Podemos afirmar que a passagem da pré-modernidade para a modernidade é marcada pela ruptura com as tradições. Segundo Renaut (1998), o traço mais específico das sociedades modernas é a "contínua dissolução das referências oriundas do passado" (p. 31). O homem pré-moderno voltava-se para seu passado, e encontrava neste uma referência normativa para seu presente. A modernidade opera uma ruptura com a tradição; "os valores do passado parecem estar singularmente enfraquecidos em benefício da celebração do presente e do novo" (p. 36). Segundo Drawin (2003), o homem moderno voltava-se para o futuro, e buscava nele as referências normativas de sua vida. O desenvolvimento da 
ciência moderna produz nos sujeitos uma aposta no que está por vir e, consequentemente, uma posição de desqualificação em relação ao idoso, pois o que interessa é o jovem, com sua longa possibilidade de futuro.

A pós-modernidade é caracterizada pela ruptura com o passado e/ou com o futuro. Vive-se a imediaticidade do agora. Não há história, pois não importam o passado ou o futuro. $\mathrm{O}$ presente adquire uma dimensão tirânica e perversa. $\mathrm{O}$ futuro deixou de ser uma aposta; o passado não é respeitado como referencial - só resta a vacuidade do presente. Nesse tempo impera o efêmero, o fugaz, e o culto ao corpo jovem. Assim, a visão do idoso, com seu corpo marcado pelo tempo, produz um incômodo. Segundo Lasch (1983), uma das características da nossa cultura é o horror à velhice.

Assim, a cultura pós-moderna, ao mesmo tempo em que apresenta esse explícito horror à velhice, é também o momento histórico em que assistimos a um aumento das pesquisas sobre envelhecimento. A crença, vigente em momento anterior, de que o envelhecimento representava um declínio do desenvolvimento, justificava o fato de não se estudar a velhice. É somente a partir da década de 1970 que assistiremos à emergência de uma posição crítica em relação a essa concepção que desconsidera a possibilidade de desenvolvimento no interior do envelhecimento. Como exemplo desse preconceito moderno podemos citar uma pesquisa sobre inteligência desenvolvida por Yerkes (conforme citado por Neri, 2001) no exército norte-americano ao final da Primeira Guerra Mundial. A pesquisa foi realizada com homens de 18 a 60 anos, e revelou, em termos de desvio padrão, o declínio da inteligência com o envelhecimento. Esse declínio já era visível a partir dos 30 anos, e mais tarde constatou-se que ele era especialmente marcado a partir dos 60 anos. Essa posição se fundamenta no paradigma da estabilidade no desenvolvimento. Desta forma, no envelhecimento só poderia ocorrer um declínio. Será necessária uma mudança de paradigma em relação ao conceito de desenvolvimento para pensar o desenvolvimento no envelhecimento.

\section{Possibilidade para estudo do envelhecimento: Erikson, Baltes e Goulet}

A primeira mudança de posição em relação ao envelhecimento aparece na teoria de Erikson (1950/1998), em sua proposta de pensar o desenvolvimento em estágios que se organizam em torno de conflitos básicos, representativos de cada momento da vida humana. Contudo, podemos afirmar que o crescente aumento de estudos sobre o envelhecimento está relacionado às ideias de Baltes e Goulet (1970), que propõem o paradigma do Life Span, ou seja, o desenvolvimento ao longo da vida.

Todavia, é preciso salientar que a proposta de Erikson (1950/1998) para pensar o desenvolvimento humano antecede as pesquisas de Baltes e Goulet (1970) sobre o life-span. Desta forma, parece-nos justo apresentar os avanços que a teoria eriksoniana oferece para o estudo do processo de envelhecimento humano.

Para Erikson (1950/1998), a vida humana é intergeracional, e se realiza num ciclo que ele chamou de Ciclo de Vida, entendido como o processo de desenvolvimento do ser hu- mano, que começa com a história dos pais, tem continuidade na infância, passa pela idade adulta, indo até a velhice. Nesse Ciclo, cada fase da vida se relaciona de forma imbricada e profunda com as outras, e cada período da vida tem os seus desafios e suas conquistas.

Erikson (1950/1998) pensa que o desenvolvimento acontece no diálogo inter-relacional entre três categorias: o corpo, a psique e o ethos. Nas palavras do autor:

A existência humana depende, em todos os momentos, de três processos de organização que devem complementar-se. Há, seja em que ordem for, o processo biológico da organização hierárquica dos sistemas de órgãos que constituem um corpo (soma); há o processo psíquico que organiza a experiencia individual através da síntese do ego (psique) e há o processo comunal da organização cultural da interdependência das pessoas (ethos). (p. 27)

Erikson (1950/1998) propõe oito estágios do desenvolvimento humano. Cada estágio apresenta uma força sintônica e outra distônica, e a resolução de cada conflito possibilita a emergência de uma força básica ou qualidade do ego. Essa força, por sua vez, também possui uma contraparte antipática. No entanto, esse jogo de forças é constitutivo e necessário para o processo de crescimento do homem, pois este "Ser" não compartilha do destino dos outros animais, os quais se desenvolvem segundo uma adaptação instintiva. Todo o processo ocorre em um indivíduo, mas este se encontra em uma comunidade (família, escola, amigos, trabalho, religião), que oferece as condições de possibilidade para o desenvolvimento. Os estágios principais e seus subestágios são os que se seguem, e os resultados dos conflitos podem ser caracterizados como aquilo que é esperado, ou seja, a qualidade que o ego precisa agregar a si: confiança versus desconfiança, que deve ter como resultado a esperança; autonomia versus vergonha e dúvida, dando origem à vontade; iniciativa versus culpa, resultando em um propósito. Esses estágios se referem aos seres que se encontram na infância. Os posteriores são: diligência versus inferioridade, resultando em competência; identidade versus confusão de identidade, levando à fidelidade; intimidade versus isolamento, tendo o amor como resultado; generatividade versus estagnação, que promove a resposta de cuidado; e, finalmente, integridade versus desespero, levando à sabedoria.

O primeiro estágio é de importância fundamental no desenvolvimento infantil, já que determinará a capacidade do indivíduo de se relacionar com o ambiente. O resultado aguardado - esperança - será referente às experiências que despertaram certa expectativa sobre o futuro do sujeito. Para Erikson (1950/1998), a "esperança conota a qualidade mais básica da condição do 'Eu', sem a qual a vida não poderia começar ou terminar de forma significativa" (p. 56). A esperança é fruto da possibilidade de confiar. O Ser precisa apostar, acreditar na vida para que nela possa investir. Em outras palavras, o que acontece nesse momento permite ao sujeito se relacionar diante do mundo de forma que possa desejar, e acreditar que aquilo o que desejou é possível. Ocorre, assim, uma adaptação entre a pessoa e o mundo. O termo esperança, para Erikson (1950/1998), exprime claramente esse momento. 
O primeiro estágio possui também momentos de grande importância, que nos interessam para a compreensão do advento da confiança básica, momentos esses que fazem uma ponte entre o eu e o ambiente no qual a criança se insere. Erikson (1950/1998) revela que quando a esperança prevalece, ela possui a função de conduzir a imagem numinosa do outro primal, ou seja, o encontro com um sentido transcendente.

O estado numinoso reflete uma comunhão entre o indivíduo e o meio, auxiliando na constituição de um senso de eu. As construções psíquicas deste primeiro estágio serão decisivas no enfrentamento da velhice. Para Erikson (1950/1998), na velhice as defesas do ego se afrouxam. Segundo o autor, mesmo os corpos mais bem-cuidados começam a enfraquecer, e não funcionam como antes. Apesar de todos os esforços para manter a força e o controle, o corpo continua a perder sua autonomia. Na medida em que a independência e o controle são desafiados, a autoestima e a confiança enfraquecem. A esperança e a confiança, que outrora proporcionavam um sólido apoio, já não são mais os sustentáculos vigorosos de épocas anteriores. Enfrentar com fé e humildade apropriadas talvez seja o curso mais sábio.

Assim, o último estágio do desenvolvimento humano, que apresenta o conflito entre integridade do eu e desespero, produzindo como força básica ou qualidade do ego a sabedoria, e cuja força antipática seria o desdém, convoca a esperança e o sentimento numinoso produzido no primeiro estágio. Para entender o processo de construção da sabedoria como força egoica no último estágio é preciso compreender os desafios colocados pelos estágios da vida adulta. $\mathrm{O}$ adulto jovem precisa trabalhar o conflito entre a aposta na construção de uma intimidade com alguém e o movimento de isolamento. Temos o confronto entre dois aspectos: a capacidade de amar, de encontro com o outro, de construção de um projeto amoroso; e a alienação, o afastamento do outro e, consequentemente, de si. É esperado que, na resolução do conflito, o sujeito consiga construir a capacidade de amar.

A possibilidade de entrada em uma relação íntima abre espaço para a construção da fecundidade e da paternidade, ou seja, anuncia o espaço de generatividade. Nesse caso, o sujeito precisa escolher entre a generatividade e a estagnação. O sentimento de pertencimento e engajamento, a consciência da condição de sujeito cidadão, a responsabilidade social e política, a consciência da finitude e a disposição para se responsabilizar pelo outro se encontram em um extremo do conflito. No outro extremo temos o sentimento de inutilidade social, irresponsabilidade, a preocupação exagerada com o próprio eu, que inviabilizam o cuidado para com o outro. Se o sujeito se coloca na posição de se responsabilizar pelo outro, teremos a força do cuidado agregada ao eu.

Por fim, o sujeito precisa enfrentar o maior desafio: manter a integridade do eu, avaliar a vida como uma realização, mantendo a generatividade, mas orientada à cultura, e podendo considerar seu percurso com sabedoria. Assim, o idoso enfrenta a luta contra o desespero, o niilismo e a falta de sentido. Dessa maneira, a teoria de Erikson (1950/1998) nos fornece uma compreensão do envelhecimento, e pistas para uma intervenção psicológica, já que é necessário trabalhar com o idoso a integridade do eu, ou seja, valorizar a vida vivida, conectar-se com passado, presente e futuro, construir projetos e abraçar a família e a comunidade como campos de cuidado.

Reconhecemos que a teoria eriksoniana inaugura o espaço de reflexão sobre o envelhecimento, mas as pesquisas que contemplam estudos sobre o idoso encontram uma grande fonte de inspiração no paradigma do life-span (Baltes \& Goulet, 1970).

Segundo Neri (1995), Büler foi o precursor do life-span, a partir de um estudo feito com 300 autobiografias. O contato com esse material revelou que o sujeito humano é, a todo momento, convocado a se desenvolver, independentemente de sua faixa etária. No paradigma do life-span defende-se a ideia do desenvolvimento ao longo da vida. O sujeito humano sempre está em processo de desenvolvimento, ainda que na velhice se diminua a plasticidade. $\mathrm{O}$ idoso precisa estar atento às mudanças sociais, históricas, econômicas, culturais, e essas mudanças exigem novas posições subjetivas que, por sua vez, acionam mecanismos de desenvolvimento. Podemos apresentar quatro paradigmas sobre o desenvolvimento: 1) Estabilidade; 2) O desenvolvimento ordenado, cujo exemplo é a concepção de Ciclo de Vida de Erikson (1950/1998); 3) Contextual, influenciado pela cultura, pelo ambiente social (curso de vida); e 4) Dialético, flexível, influenciado por eventos normativos e não normativos. O paradigma da estabilidade pensa o envelhecimento como declínio. As ideias de desenvolvimento ordenado, contextual e dialético influenciado por eventos de vida consideram a perspectiva do desenvolvimento presente no envelhecimento.

Interessa-nos a noção de desenvolvimento dialético influenciado por eventos, pois essa concepção afeta e fomenta pesquisas brasileiras. Podemos citar o exemplo de pesquisas psicológicas que investigam a posição de idosos frente aos eventos de vida, sejam eventos normativos, como aposentadoria (Batistoni, Cupertino \& Neri, 2004; Rodrigues, Ayabe, Lunardelli \& Caneo, 2005), ou eventos não esperados (Fortes \& Neri, 2004), ou ainda eventos de vida estressantes, como morte e doença (Wathier, Wilhelm, Giacomoni \& Dell'Aglio, 2007). As pesquisas sobre a posição subjetiva do idoso frente a eventos de vida estressantes confirmam que os eventos ligados à finitude se apresentam com maior potencial de estresse. Entretanto, a pesquisa de Fortes-Burgos, Neri e Cupertino (2009) revela que "homens e mulheres diferem com relação às situações consideradas estressantes, bem como a maneira como avaliam o estresse advindo dos problemas enfrentados" (p. 74). Os estudos sobre a posição subjetiva do idoso frente aos eventos de vida trazem novas perspectivas à discussão sobre velhice bem-sucedida. É fundamental, primeiramente, não confundir senescência - envelhecimento biológico - com senilidade - envelhecimento acompanhado de patologia e doença.

O paradigma do life-span contribui para a pesquisa, sobretudo, quando propõe o modelo do desenvolvimento ao longo da vida, que segue o modelo da dialética hegeliana. Nessa proposta o evento de vida é pensando como um motor que anuncia uma crise para uma dada condição inicial, que pode ser caracterizada como uma tese. As elaborações decorrentes do encontro destes dois horizontes produzem uma antítese que deve culminar na produção de uma nova posição, ou seja, a produção da síntese. Assim, podemos pensar em uma associação interessante do life- 
-span (desenvolvimento ao longo da vida) com a ideia do desenvolvimento flexível influenciado por eventos.

Os estudos sobre velhice bem-sucedida podem privilegiar temas como longevidade e satisfação com a vida. Entretanto, o estudo sobre os efeitos dos eventos de vida não esperados no envelhecimento, dentro do paradigma do desenvolvimento ao logo da vida (life-span), pode ampliar as definições de velhice bem-sucedida. Os eventos de vida convocam o sujeito para rever os recursos do self e criar novos recursos. Assim, a possibilidade de estudos e pesquisas com idosos ganha um novo terreno.

O saber psicológico tem investido na produção de pesquisas sobre o envelhecimento. Todavia, segundo Prado e Sayd (2004), os grupos que se voltam especificamente para o estudo do processo de envelhecimento humano são oriundos das ciências da saúde e das ciências biológicas, especificamente da saúde coletiva, da medicina, da enfermagem e da odontologia. Esses grupos foram criados a partir de 1995, mas os grupos de pesquisas em psicologia do envelhecimento ainda não se apresentam de forma significativa. Não temos, inclusive, um doutorado em psicologia que contemple o tema do envelhecimento humano - sem desconsiderar, no entanto, a sólida presença de programas de pós-graduação multidisciplinar de gerontologia e algumas linhas de pesquisa em nossos programas de doutorado. Esse quadro modifica-se com o tempo, uma vez que os preconceitos em relação ao envelhecimento são desvelados e esvaziados, abrindo espaços para diferentes pesquisas e intervenções psicológicas junto ao idoso. Ressalta-se a importância de se ampliar nos atuais programas de pós-graduação a presença de linhas de pesquisa e projetos voltados ao envelhecimento e à velhice.

\section{Considerações finais}

As questões que inviabilizaram o desenvolvimento de pesquisas que contemplem o tema do envelhecimento e da velhice vêm sendo superadas com atitude científica, mudanças de paradigma e posicionamento crítico. Não parece excessivo reafirmar que o novo olhar sobre o envelhecimento e a velhice tem como precursor a proposta de Erikson (1950/1998), mas o aumento das pesquisas se relaciona com o paradigma do life-span. Segundo Neri (2001), o paradigma do life-span tem fundamento epistemológico diferente da teoria eriksoniana, porque o primeiro apresenta a ideia de causalidade dialética, ou seja, os eventos de vida convocam o sujeito a operar mudanças na vida que seguem o modelo da tese, antítese e síntese, sendo que a síntese contém elementos da tese suprassumidos na síntese. $\mathrm{O}$ conceito de evento de vida pode ser pensado como um evento de transição que representa uma ponte entre dois pontos relativamente estáveis, entre os quais há um desequilíbrio, sendo que esse convoca o sujeito ao crescimento (Fortes \& Neri, 2004). Não podemos, contudo, negar a influência da teoria eriksoniana do Ciclo de Vida na construção da ideia do life-span (Neri, 2001).

Todavia, é preciso enfatizar que envelhecer bem não é uma responsabilidade só do indivíduo e depende da oferta de recursos como educação, urbanização, habitação, saúde, trabalho, família. Apesar de a cultura pós-moderna valorizar o corpo jovem, esbelto e belo, e de o envelhecimento ser algo do campo do outro, do estranho, não podemos negar o espaço familiar do envelhecimento em nosso próprio corpo, pois o tempo se expressa através do corpo, oferecendo-nos uma possibilidade de significação histórica. Corpo e tempo se entrecruzam no devir da existência. Assim, corpo, tempo e envelhecimento se enlaçam no desenrolar histórico da existência, oferecendo substrato para nossa vida. É possível uma conexão com a velhice produtiva tanto no campo das pesquisas científicas como no campo das vivências cotidianas.

\section{Referências}

Baltes, P. B., \& Goulet, L. R. (1970). Status and issues on life-span developmental psychology. In L. R. Goulet, \& P. B. Baltes (Eds.), Life-span developmental psychology: research and theory (pp. 4-21). New York: Academic Press.

Batistoni, S. S. T., Cupertino, A. P., \& Neri, A. L. (2004). Saúde emocional após a aposentadoria. In A. L. Neri \& M. Yassuda (Eds.), Velhice bem-sucedida: aspectos afetivos e cognitivos (pp. 91-110). Campinas: Papirus.

Drawin, C. R. (2003). O futuro da Psicologia: compromisso ético no pluralismo. In A. M. B. Bock (Ed.), Psicologia e o compromisso social (pp. 55-72). São Paulo: Cortez.

Dumont, L. (1985). Oindividualismo: uma perspectiva antropológica da ideologia moderna. Rio de Janeiro: Rocco.

Erikson, E. H. (1998). O ciclo de vida completo. Porto Alegre: Artmed. (Original publicado em 1950)

Fortes, A. C. G., \& Neri, A. L. (2004). Eventos de vida e envelhecimento humano. In A. L. Neri, \& M. Yassuda. (Eds.), Velhice bem-sucedida: aspectos afetivos e cognitivos (pp. 5170). São Paulo: Papirus.

Fortes-Burgos, A. C. G., Neri, A. L., \& Cupertino, A. P. F. B. (2009). Eventos de vida estressantes entre idosos brasileiros residentes na comunidade. Estudos de psicologia, 14(1), 69-75.

Giddens, A. (1997). A vida em uma sociedade pós-tradicional. In A. Giddens, U. Beck, \& S. Lach (Eds.), Modernização reflexiva (pp. 73-133). São Paulo: Ed. da Universidade Estadual Paulista.

Lasch, C. (1983). A cultura do narcisismo. Rio de Janeiro: Imago.

Mascaro, S. A. (2004). O que é velhice. São Paulo: Brasiliense.

Neri, A. (1995). Psicologia do envelhecimento: uma área emergente. In A. Neri (Ed.), Psicologia do envelhecimento (pp. 13-40). Campinas: Papirus.

Neri, A. (2001). Paradigmas contemporâneos sobre o desenvolvimento humano em psicologia e em sociologia. In A. Neri, A. (Ed.), Desenvolvimento e envelhecimento (pp. 1137). Campinas: Papirus.

Prado, S. D., \& Sayd, J. D. (2004). A pesquisa sobre envelhecimento humano no Brasil: grupos e linhas de pesquisa. Ciênc. saúde coletiva, 9(1), 57-67.

Renaut, A. (1998). O indivíduo: reflexões acerca da filosofia do sujeito. Rio de Janeiro: Difel.

Rodrigues, M., Ayabe, N. H., Lunardelli, M. C. F, \& Caneo, L. C. (2005). A preparação para a aposentadoria: o papel do psicólogo frente a essa questão. Revista Brasileira de Orientação Profissional, 6(1), 53-62. 
Wathier, J. L., Wilhelm F., Giacomoni F., C. H., \& Dell'Aglio, D. D. (2007). Eventos de Vida e Estratégias de Coping de Idosos Socialmente Ativos. Estudos Interdisciplinares sobre o Envelhecimento, 12, 35-52. Retrieved from http:// seer.ufrgs. br/RevEnvelhecer/article/view/4978/2847

Recebido em 05.06.2010 Primeira decisão editorial em 10.03.2011 Versão final em 17.09.2012 Aceito em 17.09.2012 
